\title{
The best hypoglycaemia avoidance initiative in the UK
}

\author{
UMESH DASHORA, ${ }^{1}$ MIKE SAMPSON, ${ }^{2}$ ERWIN CASTRO, ${ }^{1}$ DEBBIE STANISSTREET, ${ }^{3}$ ROWAN HILLSON ${ }^{4}$ \\ ON BEHALF OF JOINT BRITISH DIABETES SOCIETIES FOR INPATIENT CARE
}

\begin{abstract}
Introduction: The annual National Diabetes Inpatient Audit (NaDIA) in the UK continues to show a high incidence of hypoglycaemia in people with diabetes admitted to hospital. It is clear that initiatives are urgently required to address this risk.

Methods: The Joint British Diabetes Societies for Inpatient Care (JBDS-IP) organised the second national Rowan Hillson Insulin Safety Award on the theme of the best hypoglycaemia avoidance initiative in the country.

Results: The Ipswich Hospital diabetes team won the award for their innovative scheme to identify patients likely to develop hypoglycaemia through network meters and prevent the risk. The Royal Cornwall Hospital diabetes team came second, securing an award for their simulation project to educate the ward staff in managing hypoglycaemia and preventing re-occurrence. There were five other high quality entries to the competition with innovations that have the potential to reduce hypoglycaemia nationally.

Conclusions: These and similar schemes need to be developed, promoted and shared to reduce hypoglycaemia in hospitalised patients with diabetes.

Br J Diabetes 2017;17:74-77
\end{abstract}

Key words: hypoglycaemia, avoidance, initiative, UK, insulin

\section{Introduction}

Hypoglycaemia is a common and preventable complication with potentially major consequences. The National Diabetes Inpatient Audit (NaDIA) conducted on a single day has shown that $20 \%$ of inpatients with diabetes experience mild hypoglycaemia with capillary

Diabetes and Endocrine Centre, Conquest Hospital, Hastings, UK

Elsie Bertram Diabetes Centre, Norfolk and Norwich University Hospital

NHS Trust, Norwich, UK

Lister Hospital, Hertfordshire, UK

Former National Clinical Director for Diabetes, Department of Health, UK

Address for correspondence: Dr Umesh Dashora

Consultant, Diabetes and Endocrinology, Conquest Hospital, The Ridge,

St Leonards on Sea, East Sussex TN7 7RD, UK

Tel: +44 (0)1424 755255

E-mail: U.dashora@nhs.net

http://dx.doi.org/10.15277/bjd.2017.126 blood glucose (CBG) $3.0-3.9 \mathrm{mmol} / \mathrm{L}$ and $10 \%$ of patients have severe hypoglycaemia with CBG $<3.0 \mathrm{mmol} / \mathrm{L} .^{1}$ It is difficult to compare this with the frequency of hypoglycaemia in the community, but the prevalence of hypoglycaemia in population-based studies has been reported as $11-14 \%$ in a year, ${ }^{2}$ and can be as high as $96 \%$ if the period of survey is extended to any time in the past. ${ }^{3}$ Since the first NaDIA, a number of attempts such as e-learning modules, the 'Think Glucose' programme, education of junior doctors regarding hypoglycaemia during their induction and modifications in the prescription charts have been made to reduce inpatient hypoglycaemia. Unfortunately the improvements have not been huge, with the percentage of patients experiencing mild hypoglycaemia and major hypoglycaemia being refractory at about $20 \%$ and $10 \%$, respectively, in year-by-year audits. ${ }^{1}$ Worryingly, NaDIA also showed that the proportion of patients with hypoglycaemia in a specific group of patients like those with type 1 diabetes and insulin-treated patients with type 2 diabetes is much higher at $48.5 \%$ and $34.5 \%$, respectively. ${ }^{1}$

Inpatient hypoglycaemia and glycaemic variability is known to be associated with high mortality and morbidity. 4,5 Hypoglycaemia was associated with an increase in the risk of inpatient death by $85.3 \%$ and an increase in the risk of death within 1 year by $65.8 \%$ in one study. ${ }^{6}$ Length of stay increased by 2.5 days for each day of hypoglycaemia in this study. ${ }^{6}$ Hypoglycaemia increases healthcare expenditure per patient to $f 2,235$, which is $40 \%$ higher than for patients who do not have inpatient hypoglycaemia.7 Preventing hypoglycaemia in hospitalised patients with considerable ill-health and changing food intake can be quite challenging, particularly when the nursing staff and junior doctors change frequently and are under pressure. ${ }^{8}$

The Joint British Diabetes Societies (JBDS) therefore launched a national competition in 2015 to find innovations with a positive impact on hypoglycaemia so that the best and effective practices can be identified, rewarded and shared with other Trusts in the country.

\section{Methods}

The JBDS chaired by Professor Mike Sampson constantly strives to improve diabetes care for inpatients in the UK. In 2014 the JBDS formed an insulin safety group led by Dr Umesh Dashora, Erwin Castro and Debbie Stanisstreet. The group started a national competition named after the outgoing national clinical director of diabetes. The first round of the Rowan Hillson Insulin Safety Award in 2014 was hugely successful and attracted 41 
entries. ${ }^{9}$ The competition eventually led to the identification of 'best in class insulin prescription charts' which are now available on the Association of British Clinical Diabetologists' website for others to share and improve. ${ }^{10}$

In 2015, following a similar approach, a national announcement was made through websites of the Association of British Clinical Diabetologists, Diabetes UK, Diabetes In-patient Specialist Nurses and Clinical Pharmacy to invite entries for novel initiatives to reduce inpatient hypoglycaemia. ${ }^{11}$ The announcement included details of the competition and the criteria on which the entries would be judged. The entries were judged by an independent panel of judges chaired by Dr Rowan Hillson and based on predefined criteria prepared by the insulin safety group. The main criteria were novelty, rationale, effectiveness, adaptability, dissemination, publications, sustainability, funding, feedback received, evaluation, supporting material and cost-effectiveness of the initiative.

\section{Results}

Seven Trusts submitted their projects. Ipswich Hospital diabetes team won the competition and Royal Cornwall Hospital diabetes team came runners-up. All the seven entries are summarised below.

Ipswich Hospital NHS Trust: Innovative use of ward glucose monitoring system to reduce inpatient hypoglycaemia

Dr Gerry Rayman and colleagues described their initiative of adapting the Abbott Precision Xceed Pro ${ }^{\mathrm{TM}}$ monitoring system on the wards to create alerts for out of range glucose levels for the appropriate action by the nursing team. The adaptation required close collaboration between Abbott and the hospital IT department to create a system which would extract clinically meaningful data from the downloads of the ward CBG monitoring incidents. The download was developed further to transfer the dependence from an Ethernet-linked system to a WiFi-based system so that it could be easily accessed by the diabetes teams. They found that hypoglycaemia tended to occur more frequently at night and before breakfast and was more frequent if the patient was taking sulphonylureas. This led to the practice of a prescribed bedtime snack and a more proactive review of the medications on admission. These initiatives resulted in a $46 \%$ reduction in severe hypoglycaemia, $80 \%$ reduction in recurrent hypoglycaemia, 68\% reduction in the need for intravenous glucose rescue treatment, reduction in length of stay by one day $(p<0.01)$ and possible reduction in unadjusted mortality from $6.7 \%$ to $4.8 \%(p=0.01)$. There was a $20 \%$ reduction in blood glucose monitoring strip utilisation over this period. The initiative can be replicated easily by other Trusts. The project does, however, require active involvement and ongoing engagement of managers and IT departments. The group has already published their work in parts in international journals to share best practice. ${ }^{12,13}$

The judges particularly liked the fact that the innovation was comprehensive, multicentred, impactful and was shared well nationally through presentations and publications in reputed journals.
Royal Cornwall Hospital Trust: Simulation training at the point of care

The runners-up from Royal Cornwall Hospital Trust, Truro (Amanda Davis and colleagues) aimed to reduce hypoglycaemia by instituting simulation training for the ward staff. The project was conceived following a fatal incident of hypoglycaemia in the hospital. The training was delivered using a human patient simulator having severe hypoglycaemia in the ward setting to the whole ward team in real time. It required one hour for the scenario and debrief. The project was planned in a systematic fashion using the principles of the Review, Agree, Implement and Demonstrate (RAID) model. There was active engagement of ward managers, governance leads, the simulation team and the Learning and Development team. The staff reported improvement in their knowledge of the correct management of hypoglycaemia and available resources on the ward. Although formal quantitative evaluation was not done, an anecdotal increase was noted in staff recognition of hypoglycaemia and reduction in serious untoward incidents linked to severe hypoglycaemia. Many useful actions resulted from running the simulation session including 'glucagon in fridge' stickers for all wards and inclusion of training for drawing up intravenous glucose in the competency framework for the nursing staff. The project was presented at the third National Diabetes Inpatient Conference, which resulted in numerous enquiries regarding implementation of point of care simulation in other Trusts. Many lessons were learned during the implementation of the project including the need for standardisation of stocking and supply of glucagon and the need for engaging ward managers to deliver these sessions. Feedback for these sessions was systematically collected and scored between 8 and 9 , with 10 being excellent.

The judges particularly liked the innovative, adaptable, reallife and memorable nature of the project, along with the excellent feedback received by the team.

\section{University Hospitals of Leicester: Inpatient diabetes education through animation (IDEA)}

Sowmya Gururaj and colleagues produced a number of short (3-4 minute) animations embedded into a YouTube channel to emphasise educational points to the junior doctors and nurses (e.g. reducing insulin dose if patient is not eating well). Of the respondents seeing the videos, $89 \%$ or more rated them 4 or higher with 5 being excellent. The videos had over 15,000 hits on YouTube at the time of submission. https://www.youtube.com/channel/UCEjm7H zssu04snzzoxTD85A

The judges were particularly impressed with the novelty and attraction of short video clips with very useful educational messages. They would have liked to see some hypoglycaemia outcome data on this project.

East Sussex Hospital NHS Trust: Hypoglycaemia reduction by a 9-point education system

Dr Dashora and colleagues described a comprehensive education programme targeted at all the hospital staff. It consisted of a comprehensive programme of education including monthly electronic diabyte newsletter, promotion of hypo awareness week, hypo page 
on the Trust prescription chart, study days for ward nurses and healthcare assistants, diabetes hour during induction of junior doctors, quarterly education for A\&E doctors, daily alerts from pointof-care testing networked meters, daily diabetes team ward rounds and establishment of link-nurse system on all wards in the hospital. Positive feedback was collected from all the staff groups. Some of this work has been published in peer-reviewed journals and on the national website of the Diabetes Association. 1,5,14,15

The judges liked the comprehensive system approach of the initiative. Unfortunately, there was no impact on hypoglycaemia although prescription and management errors reduced. The judges thought that the educational activities should be supported by the Trust rather than be dependent on pharmaceutical sponsorship.

\section{Bedford Hospital NHS Trust: Reduction in hypoglycaemia by multidisciplinary team work}

Dr Pan and colleagues reported a combination of interventions including education, training and improvements by a team working with the 'Think Glucose' team, pharmacists, the education team, IT and communication team and diabetes team. The team demonstrated a year-on-year reduction in hypoglycaemia despite an increase in the number of inpatients and without any increase in the inpatient diabetes team resources. The action plan was based on up-skilling and regular education and training of ward staff and junior doctors. The interventions included regular review of antidiabetic medications rather than PRN use of insulin, bedtime snacks function in the electronic prescribing system, reviewing insulin-related incidents regularly, revision of insulin prescription charts with a number of safety features, e-learning, pre-printed words like 'units', preprinted scales for variable rate intravenous insulin infusion (VRIII) and yearly hypoglycaemia audit. The hypoglycaemia rate showed a yearby-year reduction from 15\% to $11 \%$.

The judges liked the comprehensive and sustainable nature of the project. Some more data on evaluation would have made the entry stronger.

\section{Worcester Royal Acute Hospital Trust: Using the Precision Webb system to reduce hypoglycaemia}

Dr Young and colleagues used the Abbott Precision Webb system remotely to identify patients likely to have hypoglycaemia and initiated an action plan to prevent them. The team interrogated the databases daily and reviewed patients with low CBG levels ( $<3 \mathrm{mmol} / \mathrm{L})$. The approach reduced hypoglycaemic episodes by $47 \%$ with no additional increase in the diabetes specialist nurse (DSN) workload.

The judges were particularly impressed with the reduction in hypoglycaemia and the resource-neutrality of the project, but would have liked some details on the time taken to interrogate the system and feedback from the users. Outcomes like length of stay would have strengthened the entry.

Colchester Hospital University Foundation Trust: Reduction in admission and re-admission rates for severe hypoglycaemia

Turner and colleagues at Colchester liaised with the ambulance serv-

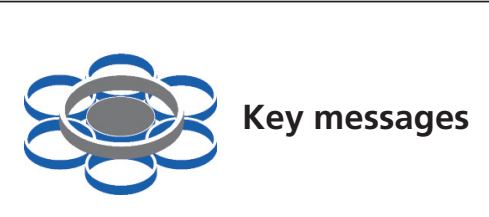

- Hypoglycaemia in hospitalised people with diabetes continues to be a significant issue in the UK

- The Joint British Diabetes Societies for Inpatient Care organised a national competition to find the most effective initiatives to reduce hypoglycaemia

- Use of network meters to identify and protect patients at risk of hypoglycaemia, educational initiatives like simulation projects, short animations and electronic newsletters, multidisciplinary team work, regular medication review, prompts for bedtime snacks and realistic capillary blood glucose targets for inpatients were judged to be very effective in reducing hypoglycaemia

ice and local healthcare teams to prevent admission and readmission of patients with severe hypoglycaemia by starting inpatient visits by a hypo DSN to key areas like A\&E and Emergency Assessment Units. All referrals for hypoglycaemia were triaged by hypo DSN and a plan of care was initiated involving hypo DSN, community DSN and multidisciplinary specialist team. The action plan included promotion of 'Think Glucose' assessments, use of an inpatient spreadsheet, electronic discharge summary and intensive telephone follow-up, review of medications, educational support and liaison with the other multidisciplinary team members, home visits and structured education for care home staff. The intervention resulted in a reduction in the readmission rate from 3 to 1 for a similar number of admissions (26 and 27) during May-July 2015 compared with the same period in 2014. Ambulance crew were informed of the follow-up plan for individual patients, increasing their awareness of the support available for these patients.

The judges appreciated the breadth of this project but would have liked to see some more evaluation of the initiative and perhaps some details on the referral pathways before and after the initiative.

\section{Summary and conclusions}

The competition revealed some excellent practices that can be used and adapted by other Trusts to reduce hypoglycaemia in hospital inpatients with diabetes. Most initiatives required team-working within the diabetes team and with others in the hospital, and sometimes with outside teams like ambulance services and community teams.

The most effective initiative in reducing inpatient hypoglycaemia and length of stay appears to be an adaptation of network meters to trigger a preventive response from the diabetes team for at-risk patients. Reviewing medications at the time of hospital admission and stopping or reducing medications like sulphonylureas and insulin capable of causing hypoglycaemia would help. The Trusts 
should consider putting a prompt in their prescribing systems for bedtime snacks. We recommend that glucose control during the hospital stay should be more realistic and should aim for levels of 6-10 $\mathrm{mmol} / \mathrm{L}$, with a range of $4-12 \mathrm{mmol} / \mathrm{L}$ being acceptable for patients on VRIII. ${ }^{16,17}$ The American Diabetes Association recommends a target glucose level of 7.8 and $10 \mathrm{mmol} / \mathrm{L}$ for all inpatients with diabetes on insulin treatment in general, although lower or higher targets may be necessary in specific circumstances. ${ }^{18}$ In patients with previous tight control reflected by $\mathrm{HbA}_{1 c}$ of 48 or below, extra caution should be exercised. Education of hospital staff remains crucial and Trusts should fund these educational activities, reducing the reliance on pharmaceutical companies.

Acknowledgement The authors are grateful to Christine Jones who provided administrative support for this project.

\section{Conflict of interest None \\ Funding None}

\section{References}

1. Health and Social Care Information Centre. National Diabetes Inpatient Audit 2015. http://content.digital.nhs.uk/catalogue/PUB20206/nati-diabinp-audi-15-nat-rep.pdf (accessed 21 Sep 2016)

2. Tschöpe D, Bramlage P, Binz C, et al. Incidence and predictors of hypoglycaemia in type 2 diabetes - an analysis of the prospective DiaRegis registry. BMC Endocrine Disorders 2012;12:23.

http://dx.doi.org/10.1186/1472-6823-12-23

3. Shriraam V, Mahadevan S, Anitharani M, et al. Reported hypoglycemia in type 2 diabetes mellitus patients: prevalence and practices - a hospital-based study. Indian J Endocrinol Metab 2017;21:148-53. http://dx.doi.org/10.4103/2230-8210.196002

4. Timmons JG, Cunningham SG, Sainsbury CA, Jones GC. Inpatient glycemic variability and long-term mortality in hospitalized patients with type 2 diabetes. J Diabetes Complications 2016;31:479-82. http://dx.doi.org/10.1016/j.jdiacomp.2016.06.013

5. Yeh JS, Sung SH, Huang HM, et al. Hypoglycemia and risk of vascular events and mortality: a systematic review and meta-analysis. Acta Diabetol 2016;53:377-92. http://dx.doi.org/10.1007/s00592-015-0803-3

6. Turchin A, Matheny ME, Shubina M, Scanlon JV, Greenwood B, Prendergrass ML. Hypoglycemia and clinical outcomes in patients with diabetes hospitalized in the general ward. Diabetes Care 2009;32:1153-7. http://dx.doi.org/10.2337/dc08-2127

7. McEwan P, Thorsted BL, Wolden M, et al. Healthcare resource implica- tions of hypoglycemia-related hospital admissions and inpatient hypoglycemia: retrospective record-linked cohort studies in England. BMJ Open Diabetes Res Care 2015;3:e000057.

http://dx.doi.org/10.1136/bmjdrc-2014-000057

8. Royal College of Physicians. Underfunded, underdoctored, overstretched: the NHS in 2016. https://www.rcplondon.ac.uk/guidelinespolicy/underfunded-underdoctored-overstretched-nhs-2016?utm_sourc e=Communications\&utm_medium=email\&utm_campaign=7552127_U nderfunded\%20report\%20-\%2021\%20September\%202016\&utm_ content=UnderfundedReport\&dm_i=1V12,4HV9B,JCEEBM,GM8NB, 1 (accessed 21 Sep 2016).

9. Dashora U, Sampson M, Castro E, Stannisstreet D, Hillson R, on behalf of the Joint British Diabetes Societies for Inpatient Care. Rowan Hillson Insulin Safety Award 'best in class' insulin prescription chart competition. Br J Diabetes 2015;15:135-8.

http://dx.doi.org/org/10.15277/bjdvd.2015.028

10. Sampson M. Best in class insulin prescription charts. http://www.diabetologists-abcd.org.uk/JBDS/insulin_chart_winners.pdf (accessed 21 Sep 2016)

11. Gregory R. Rowan Hillson Insulin Safety Award 2015. http://www.diabetologists-abcd.org.uk/Lists/Announcements/DispForm.htm?ID= 218\&Source=http \% 3a\%2f\%2fwww\%2ediabetologists \% 2dabcd\%2eo rg\%2euk\%2fhome\%2ehtm. (accessed 21 Sep 2016).

12. Rajendran R, Kerry C, Rayman G, et al. Temporal patterns of hypoglycaemia and burden of sulfonylurea-related hypoglycaemia in UK hospitals: a retrospective multicentre audit of hospitalised patients with diabetes. BMJ Open 2014;4:e005165. http://dx.doi.org/10.1136/bmjopen-2014-005165

13. Kerry C, Mitchell S, Sharma S, Scott A, Rayman G. Diurnal temporal patterns of hypoglycaemia in hospitalized people with diabetes may reveal potentially correctable factors. Diabet Med 2013;30:1403-06. http://dx.doi.org/10.1111/dme.12256

14. Jones S, Castro E, Dashora U. Management of inpatients with diabetes undergoing surgery using pre-printed variable rate intravenous insulin infusion prescriptions. J Diabetes Nursing 2016;20:202-06.

15. Dashora U, Castro E. Best in class insulin prescription charts. http://www. diabetologists-abcd.org.uk/Posters/Autumn2014/ Dashora.pdf

16. George S, Dale J, Stanisstreet D. A guideline for the use of variable rate intravenous insulin infusion in medical inpatients. Diabet Med 2015;32:706-13. http://dx.doi.org/10.1111/dme.12756

17. Barker P, Creasey PE, Dhatariya K, et al. Peri-operative management of the surgical patient with diabetes 2015. Anaesthesia 2015;70:1427-40. http://dx.doi.org/10.1111/anae.13233

18. American Diabetes Association. Diabetes care in the hospital. Diabetes Care 2017;40(Suppl 1):S120-7. http://dx.doi.org/10.2337/dc17-S017 